\title{
Significance of $\mathrm{HCO}_{3}{ }^{-}$alkalinity in calcification and utilization of dissolved inorganic carbon in Chara vulgaris
}

\author{
Heyun Wang ${ }^{1,2}$, Leyi $\mathrm{Ni}^{2, *}$, Dan $\mathrm{Yu}^{3}$ \\ ${ }^{1}$ College of Resource and Environmental Engineering, Hubei University of Technology, Wuhan 430068, PR China \\ ${ }^{2}$ Donghu Experimental Station of Lake Ecosystems, \\ State Key Laboratory for Freshwater Ecology and Biotechnology of China, Institute of Hydrobiology, The Chinese Academy \\ of Sciences, Donghu South Road 7, Wuhan 430072, PR China \\ ${ }^{3}$ Freshwater National Observation and Research Station of Lake Ecosystem in Liangzi Lake, College of Life Sciences, \\ Wuhan University, Wuhan 430072, PR China
}

\begin{abstract}
To investigate the influence of $\mathrm{HCO}_{3}{ }^{-}$alkalinity on calcification in thalli of the genus Chara, we studied the effects of increased light level and additional $\mathrm{HCO}_{3}{ }^{-}$on calcification rate in C. vulgaris at various hours ( $30 \mathrm{~min}, 8 \mathrm{~h}, 12 \mathrm{~h}, 12.5 \mathrm{~h}, 20 \mathrm{~h}$ and $24 \mathrm{~h}$ after treatment) in a $24 \mathrm{~h}$ experiment (12 h light:12 h dark). We identified a significant Pearson's correlation between exogenous

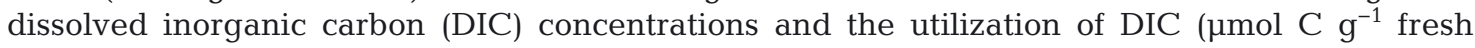
weight). Plotting the daily rhythm of DIC utilization produced negative quadratic curves. Furthermore, calcification rate $\left(\mu \mathrm{mol} \mathrm{Ca} \mathrm{h}^{-1} \mathrm{~g}^{-1}\right)$ was linearly related to DIC utilization rate $\left(\mathrm{DIC}_{\text {uptakei }}\right.$

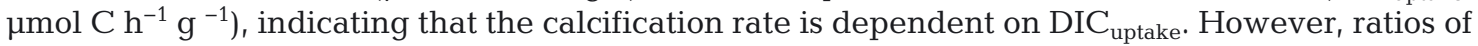
calcification to the utilization of DIC were decreased at high light intensity and increased with $\mathrm{HCO}_{3}{ }^{-}$addition, which was mainly ascribed to changes in the ratio of calcification to photosynthesis. Chlorophyll fluorescence results provided direct evidence for the promotion of photosynthesis in Chara thalli by both high light and DIC addition and their positive influence on maximum relative electron transport rate. These results suggest that calcification in calcareous $C$. vulgaris is mainly restrained by $\mathrm{HCO}_{3}{ }^{-}$alkalinity, which could explain the correlation between calcification of Chara thalli and alkalinity of water bodies in the field.
\end{abstract}

KEY WORDS: Calcification · Dissolved inorganic carbon utilization · Rapid light curves $\cdot$ Chara Calcification $\cdot$ Photosynthesis

\section{INTRODUCTION}

$\mathrm{CaCO}_{3}$ encrustations are common on the stems, branchlets, and surfaces of oogonia in Chara spp. (hereafter 'Chara') (Wood \& Imahori 1965). However, intra- and inter-specific variations in the external encrustations on the cell wall are present within this genus (Anadón et al. 2002), as well as between ecorticate species and corticated species (Kawahata et al. 2013). Furthermore the average percentage content of encrustation in dry charophyte mass varied from $15 \%$ (Siong \& Asaeda 2009a) to $60 \%$ (Hutchinson

*Corresponding author: nily@ihb.ac.cn
1975), $61.5 \%$ (Kufel et al. 2013), $70 \%$ (Blindow 1992), and $77 \%$ (Urbaniak 2010), depending on the studied species and the water environment where those species were collected. However, carbonate deposited by dense charophyte vegetation accounts for a significant portion of calcium carbonate in the sediments of so-called Chara lakes and represents an important record of environmental conditions (Apolinarska et al. 2011, Pelechaty et al. 2013, Kufel \& Strzałek 2016).

Light and dissolved inorganic carbon (DIC) are 2 of the most important environmental variables that affect the morphology and distribution of Chara plants

(C) The authors 2017. Open Access under Creative Commons by Attribution Licence. Use, distribution and reproduction are unrestricted. Authors and original publication must be credited. 
(McConnaughey 1998) because of their fast attenuation and limited solubility in the water column, respectively. In natural habitats, most calcareous species of Chara inhabit waters of relatively high alkalinity and calcium content (Kufel \& Kufel 2002). Obvious encrustation has been observed under high light intensity (Wang 2008). However, there is much debate on the influence of light and $\mathrm{HCO}_{3}{ }^{-}$alkalinity on calcification. According to the cis-calcification model, calcification on alkaline surfaces of Chara is a by-product of bicarbonate assimilation from alkaline water, and light therefore promotes calcification (McConnaughey \& Whelan 1997). However, in the trans-calcification model, $\mathrm{Ca}^{2+}-2 \mathrm{H}^{+}$exchange catalysed by $\mathrm{Ca}^{2+}$ ATPase is responsible for calcification in Chara (McConnaughey \& Falk 1991). Therefore, in the trans-calcification model, calcification does not require light, and calcification functions as a proton generator. Since the 1990s, many studies have demonstrated the beneficial effects for macrophytes from proton generation by calcification and how this is related to bicarbonate utilization (McConnaughey 1991, McConnaughey \& Falk 1991), nutrient assimilation (McConnaughey \& Whelan 1997, Siong \& Asaeda 2006, 2009b, Gomes \& Asaeda 2010, Wang et al. 2013), and hyper-accumulation of heavy metals (McConnaughey 1991, Siong \& Asaeda 2009a). Furthermore, Wang et al. (2013) demonstrated that calcification could mitigate the toxic effects of high $\mathrm{NH}_{4}$ $\mathrm{N}$ on calcareous Chara plants.

In mildly alkaline water, DIC is typically decreased in 2 ways, either by uptake through the photosynthesis of algae or by becoming incorporated into the cell walls of calcareous Chara by calcification (Ray et al. 2003). Owing to the sound understanding of the relationships between fluorescence parameters and photosynthetic electron transport in vivo (Maxwell \& Johnson 2000, Baker 2008), fluorescence parameters such as photosynthetic efficiency estimates $\left(F_{\mathrm{v}} / F_{\mathrm{m}}\right)$ have been widely used to assess the photosynthetic characteristics of submerged plants or macroalgae (Schwarz et al. 2000 and Durako \& Kunzelman 2002 for seagrass, Beer \& Axelsson 2004 for macroalgae, Asaeda et al. 2014 for Chara spp.). In addition, the rapid light curve (RLC) is a powerful tool for the assessment of photosynthetic performance and for providing detailed information on the saturation characteristics of electron transport (Ralph \& Gademann 2005).

C. vulgaris $\mathrm{L}$. is a polymorphic charophyte with a worldwide distribution between $70^{\circ} \mathrm{N}$ and $50^{\circ} \mathrm{S}$. C. vulgaris is prone to accumulate lime and form apparently non-banded encrustation on its stems (Anadón et al. 2002), accounting for more than $60 \%$ of ash mass under $50 \%$ of sunlight (Wang et al. 2008). To clarify the influence of light and $\mathrm{HCO}_{3}{ }^{-}$-alkalinity on calcification, we investigated the effects of high light intensity and $\mathrm{HCO}_{3}{ }^{-}$addition on the calcification rate of $C$. vulgaris by using an open experimental system. Furthermore, RLC was used to assess the effects of light level increase and $\mathrm{HCO}_{3}{ }^{-}$addition on photosynthetic performance. The aims of this study were to: (1) investigate the occurrence of dark calcification by monitoring the daily rhythm of the calcification rate of Chara thalli under constant light and (2) identify the rate-limiting factor for calcification of calcareous plants.

\section{MATERIALS AND METHODS}

\section{Plant culture}

On 5 April 2010, 24 clusters of shoots (10-15 cm in length) of Chara vulgaris were collected from a depth of $1-1.5 \mathrm{~m}$ in Liangzi Lake $\left(30^{\circ} 05^{\prime}\right.$ to $30^{\circ} 18^{\prime} \mathrm{N}$, $114^{\circ} 21^{\prime} \mathrm{E}$ to $114^{\circ} 39^{\prime} \mathrm{E}$ ), a shallow lake located in the middle reach of the Yangtze River in China. These specimens were then transplanted into 3 cylindrical aquaria (1 $\mathrm{m}$ in radius) located at Donghu Experimental Station of Lake Ecosystems, Institute of Hydrobiology, Chinese Academy of Sciences. These aquaria were filled with tap water and sediment from the Tanglinhu area, as described by Feng et al. (2006). After $1 \mathrm{mo}$, the shoots of the plants had developed towards the water surface, with a branched morphology and visible calcified encrustation on the internodes. On 15 May 2010, more than 120 apical tips with 3 or 4 internodes (about $4-5 \mathrm{~cm}$ in length) were cut using scissors and pre-incubated in 11 glass beakers $(n=4)$ filled with plant-containing water (PCW). To avoid the effect of $\mathrm{Ca}^{2+}$ and $\mathrm{Mg}^{2+}$ contents on calcification, PCW was obtained by filtering water from the previously used circle aquaria through GF/C membranes (Whatman), with DIC content of $0.98 \pm 0.04 \mathrm{mM} \mathrm{C}_{1} \mathrm{Ca}^{2+}$ content above $60 \mathrm{mg} \mathrm{l}^{-1}$ and $\mathrm{Mg}^{2+}$ content below $30 \mathrm{mg} \mathrm{l}^{-1}$ (McConnaughey 1998, Kufel \& Kufel 2002, Gomes \& Asaeda 2010, Asaeda et al. 2014). All beakers were placed in the plant growth incubator under controlled conditions: temperature, $25 \pm 2{ }^{\circ} \mathrm{C}$; illumination on the water surface, $90 \mu \mathrm{mol}$ $\mathrm{m}^{2} \mathrm{~s}^{-1}$; and a photoperiod of 12:12 h (light:dark). After 2 wk of pre-culture, inorganic carbon accumulated within the plants was removed by transferring all apical tips to 11 beakers containing ultrapure water for $6 \mathrm{~h}$ under the same culture conditions (Kahara \& Vermaat 2003). 


\section{Experimental design}

A factorial design of $2 \times 2$ of light intensity and DIC level was used in this experiment: low light (LL, $90 \mu \mathrm{mol} \mathrm{m}^{-2} \mathrm{~s}^{-1}$ ) and high light (HL, $150 \mu \mathrm{mol}$ $\mathrm{m}^{-2} \mathrm{~s}^{-1}$ ) intensities and low DIC (LC: no $\mathrm{HCO}_{3}{ }^{-}$ addition) and high DIC (HC: $1 \mathrm{mM} \mathrm{HCO}_{3}{ }^{-}$addition) levels. These 4 combined treatments were marked as LL-LC, LL-HC, HL-LC, and HL-HC, respectively. For each treatment, 24 flasks (4 flasks each time $\times$ 6 times) with plants were used as replicates, and 12 flasks ( 2 flasks each time $\times 6$ times) without plants were used to calibrate changes to the solution over time. At the beginning of the photoperiod (Time 0), 4 or 5 apical tips (about $0.5 \mathrm{~g}$ in fresh weight, without endogenous inorganic carbon) were weighed and transferred into 96 flasks (24 flasks $\times 4$ treatments) containing $200 \mathrm{ml}$ of the culture solution. In all, 144 conical flasks (96 flasks + [12 flasks $\times 4]$ ) with a capacity of $250 \mathrm{ml}$ were placed in 2 plant incubators with different light levels (each contained 72 flasks), with the same temperature conditions as for pre-culture. The addition of $\mathrm{HCO}_{3}{ }^{-}$was made by adding $\mathrm{NaHCO}_{3}$, and the $\mathrm{pH}$ of the culture solutions was adjusted to 8.2 by using $0.1 \mathrm{M}$ $\mathrm{NaOH}$ (before being decanted into the flasks).

\section{Experimental sampling and measurement}

To study the utilization of DIC and calcification rate during the day and night, at various hours (30 $\mathrm{min}$, $8 \mathrm{~h}, 12 \mathrm{~h}, 12.5 \mathrm{~h}, 20 \mathrm{~h}$ and $24 \mathrm{~h}$ after treatment), $20 \mathrm{ml}$ of the solution were removed and stored at $-20^{\circ} \mathrm{C}$ $(10 \mathrm{ml}$ for DIC analysis and $10 \mathrm{ml}$ for ion content measurement). Four flasks with plants and 2 flasks without plants were used for each point of the daily cycle. The DIC content of the solution was measured using a total organic carbon analyser (O.I. analytical 1010). Analyses of cation content were performed using a Dionex DX100 ion chromatograph equipped with a $25 \mu$ l sample loop, a cation-exchange column and a suppressed conductivity detection system. For separation, an ion Pac CG10A guard column $(50 \times$ $4 \mathrm{~mm}$ ) was coupled to an IonPac CS10A analytical column $(250 \times 4 \mathrm{~mm})$. A Dionex CSRS ultra selfregeneration suppressor was employed, and the 2.0 software was used for system control and data acquisition. All IC-related equipment was supplied by Dionex.

Pulse-amplitude modulated (PAM) chlorophyll fluorescence parameters were monitored using a submersible PAM fluorometer (diving-PAM; Walz).
RLCs were generated for branchlets mounted in the chamber. According to the procedure of Ralph \& Gademann (2005), RLCs were generated using a pre-installed software routine, where the actinic light was increased in 8 steps (plus initial quasidarkness measurement) beginning at an initial irradiance for a prescribed duration. To allow relative electron transport rate (rETR) to reach a plateau (over at least 2 points) and decline during the last light steps, 8 consecutively increasing actinic light intensities of $3,16,42,77,125,187,339$ and $501 \mu \mathrm{mol}$ $\mathrm{m}^{-2} \mathrm{~s}^{-1}$ were used. The first saturating pulse occurred after the quasi-darkness period. The second to ninth measurements occurred after a stepped actinic irradiation of $10 \mathrm{~s}$ duration, from 3 to $501 \mu \mathrm{mol}$ photons $\mathrm{m}^{-2} \mathrm{~s}^{-1}$. An RLC takes approximately $90 \mathrm{~s}$ and records fluorescence yield $(F)$, maximum fluorescence yield of a light-adapted leaf $\left(F^{\prime}{ }_{m}\right)$, effective quantum yield of PSII (ФPSII), and ETR, which can be plotted as a function of photosynthetically active radiation (PAR) irradiance. To quantitatively compare RLCs under different treatments, they were described by several character parameters: $\alpha$ (photosynthetic rate in the light-limited region of RLC), Ek (minimum saturating irradiance) and rETRm (maximum rETR), determined by non-linear regression with the empirical equation proposed by Platt et al. (1980).

\section{Calculation and analysis}

DIC uptake by plants in each sample was calculated as the difference of DIC content in the solution with plants and the means of DIC content in 2 flasks without plants. A similar approach was used for $\mathrm{Ca}^{2+}$ uptake. To avoid the effect of the pre-experiment fresh weight of plants, utilization of DIC at each sampling time was expressed as $\mu \mathrm{mol} \mathrm{C} \mathrm{g}^{-1}$ fresh weight, while calcification was expressed as $\mu \mathrm{mol} \mathrm{Ca} \mathrm{g}^{-1}$ fresh weight. To study the daily rhythm of calcification, calcification rate was defined as $\mu \mathrm{mol} \mathrm{Ca} \mathrm{h}{ }^{-1} \mathrm{~g}^{-1}$ of fresh weight $\left(\mathrm{Ca}^{2+}\right.$ uptake); similarly, utilization rate of DIC was expressed as $\mu \mathrm{mol} \mathrm{C} \mathrm{h}^{-1} \mathrm{~g}^{-1}$ of fresh weight (g) (DIC uptake $_{\text {. }}$.

Regression curves were used to express the time course of DIC concentration in the solution. The effects of $\mathrm{HCO}_{3}{ }^{-}$addition and light increase on the $\mathrm{Ca}^{2+}$ and DIC contents of the solution were tested using 2-way ANOVA. Pearson's correlation was used to analyse the relationship between utilization of DIC and DIC concentration, as well as calcification and DIC concentration in solution. Inverse regression 
curves were used to express the time course of

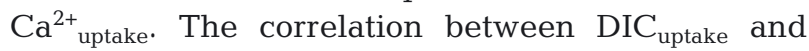
$\mathrm{Ca}^{2+}$ uptake was calculated by linear regression. Nonlinear regression was used to determine the character parameters of RLC, and the effects of DIC addition and light increase on the above parameters were evaluated by 2-way ANOVA. All data were analysed using SPSS 13.0.

\section{RESULTS}

\section{Effect of plants on DIC concentration in the solution}

As expected, plant photosynthesis and calcification significantly affected the DIC concentration of the solution. The variation of DIC concentration in the solution across sampling times for all treatments could be fitted to a quadratic equation, i.e. DIC concentration sharply decreased during the light period but slowly increased during the dark period (Fig. 1).
The results of 2-way ANOVA revealed that both light levels and the addition of $\mathrm{HCO}_{3}{ }^{-}$significantly affected the contents of DIC at 12 and $24 \mathrm{~h}$ sampling times (Table 1). The largest change in DIC was found in LL-HC at $12 \mathrm{~h}$ and in HL-HC at $24 \mathrm{~h}$ (Fig. 1). Addition of $\mathrm{HCO}_{3}{ }^{-}$significantly decreased the $\mathrm{pH}$ of the solution, therefore $\Delta \mathrm{pH}$ at low $\mathrm{HCO}_{3}{ }^{-}$ levels was higher than that at high $\mathrm{HCO}_{3}{ }^{-}$levels (Table 1).

\section{Variation in DIC utilization and calcification of Chara thalli}

DIC utilization ( $\mu$ mol $\mathrm{C} \mathrm{g}^{-1}$ ) followed a negative quadratic equation with sampling time (Fig. 2). Pearson's correlation showed that DIC utilization ( $\mu$ mol C $\mathrm{g}^{-1}$ ) was significantly negatively related to DIC concentration for each treatment, whereas significant correlation between calcification ( $\mu$ mol $\mathrm{Ca} \mathrm{g}^{-1}$ ) and DIC concentration only occurred under low light conditions (Table 2).

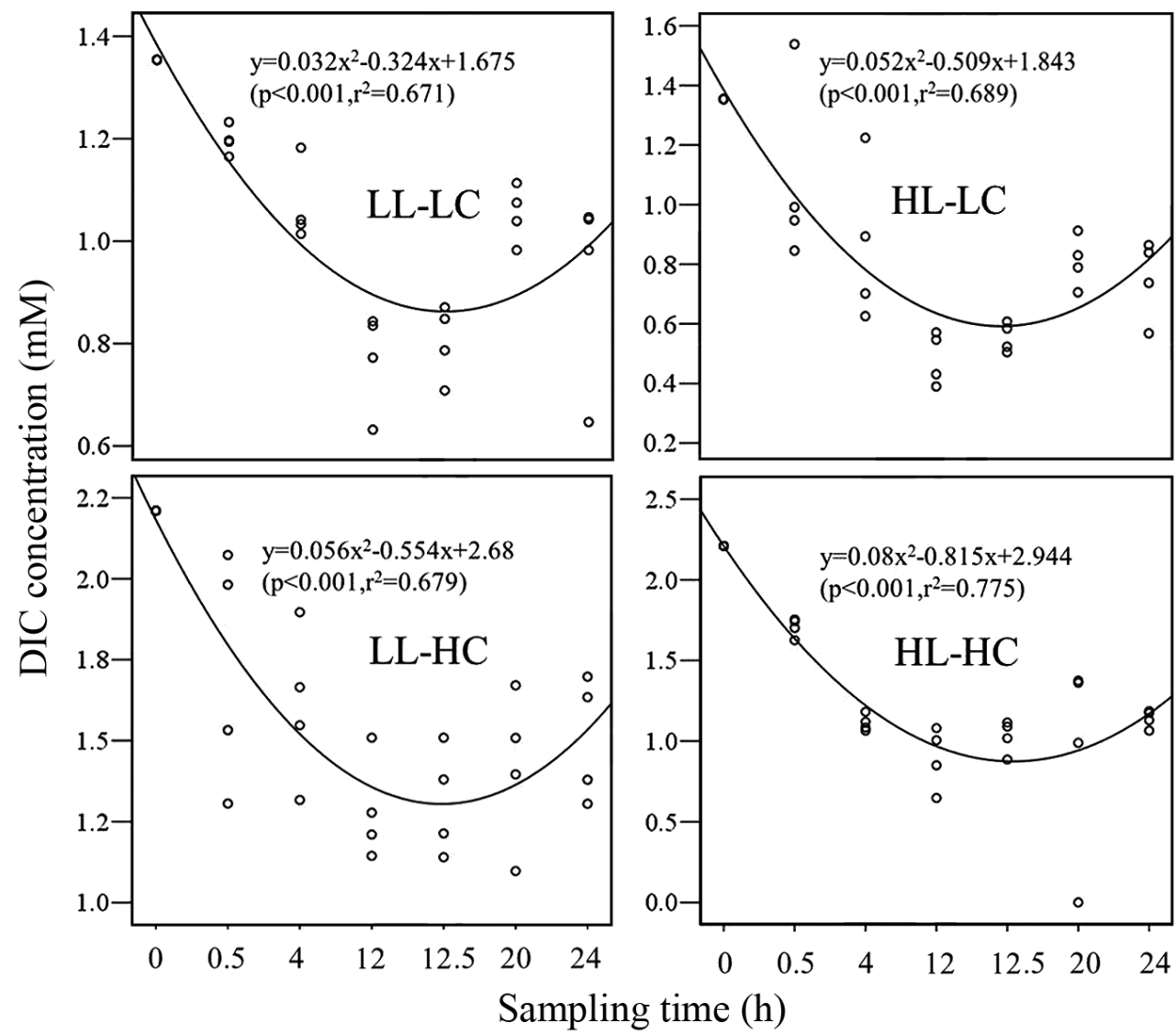

Fig. 1. Variations in the concentration of dissolved inorganic carbon (DIC) in solution with sampling time in 4 different treatments: LL-LC, LL-HC, HL-LC and HL-HC, where LL: low light $\left(90 \mu \mathrm{mol} \mathrm{m} \mathrm{m}^{-2} \mathrm{~s}^{-1}\right)$, HL: high light $\left(150 \mu \mathrm{mol} \mathrm{m}^{-2} \mathrm{~s}^{-1}\right), \mathrm{LC}$ low DIC (no $\mathrm{HCO}_{3}{ }^{-}$addition), $\mathrm{HC}$ : high DIC (1 $\mathrm{mM} \mathrm{HCO}_{3}^{-}$addition) 
Table 1. F-values and significance of 2-way ANOVA of the effects of dissolved inorganic carbon (DIC) and light level on the ratio of calcification to utilization of DIC, increased $\mathrm{pH}$ and variation in DIC both at 12 and $24 \mathrm{~h}$ for Chara vulgaris thalli. ${ }^{* * *} \mathrm{p}<0.001,{ }^{* *} \mathrm{p}<0.01,{ }^{*} \mathrm{p}<0.5, \mathrm{~ns}$ : $\mathrm{p}>0.5$

\begin{tabular}{|lrrr|}
\hline Parameter & DIC (D) & Light (L) & D $\times \mathrm{L}$ \\
\hline Ratio of calcification to utilization & $8.051^{*}$ & $18.630^{* * *}$ & $5.804^{*}$ \\
of DIC (slopes of lines) & & & \\
$\Delta \mathrm{pH}$ & $21.544^{* *}$ & $2.606 \mathrm{~ns}$ & $0.017 \mathrm{~ns}$ \\
Variation in DIC at 12 h & $9.827^{* *}$ & $27.777^{* * *}$ & $4.612 \mathrm{~ns}$ \\
Variation in DIC at 24 h & $42.529^{* * *}$ & $1.758 \mathrm{~ns}$ & $20.419^{* * *}$ \\
\hline
\end{tabular}

The highest calcification rate $\left(\mathrm{Ca}^{2+}\right.$ uptake $)$ was found at $0.5 \mathrm{~h}$, with sharp decreases in $\mathrm{Ca}^{2+}$ uptake at all subsequent time points for all treatments. An inverse regression demonstrated a significant decrease in $\mathrm{Ca}^{2+}{ }_{\text {uptake }}$ over time (Fig. 3). HL decreased $\mathrm{Ca}^{2+}{ }_{\text {uptake }}$ whereas the addition of $\mathrm{HCO}_{3}{ }^{-}$increased $\mathrm{Ca}^{2+}{ }_{\text {uptake. }}$. The calcification rate was linearly related to the utilization rate of DIC for all treatments (Fig. 4). Ratio of calcification rate to utilization of DIC rate, i.e. slopes of lines shown in Fig. 4, was higher at HC than at LC, while it was lower at HL than that at LL levels (Table 1, Fig. 4).

\section{Responses of chlorophyll fluorescence to light levels and addition of $\mathrm{HCO}_{3}^{-}$}

All plots of ETR as a function of irradiance showed the classical shape of a photosynthesis-irradiance (P-E) curve, with a linear rise in the light-limited region followed by a plateau, where PAR is above Ek and the photosynthetic pathway becomes limited (Fig. 5a). Both HL and HC significantly increased rETRm and Ek (minimum saturating irradiance). There was a significant interaction on rETRm between light level and DIC addition (Table 3). The highest rETRm was found in HL-HC (Fig. 5b).

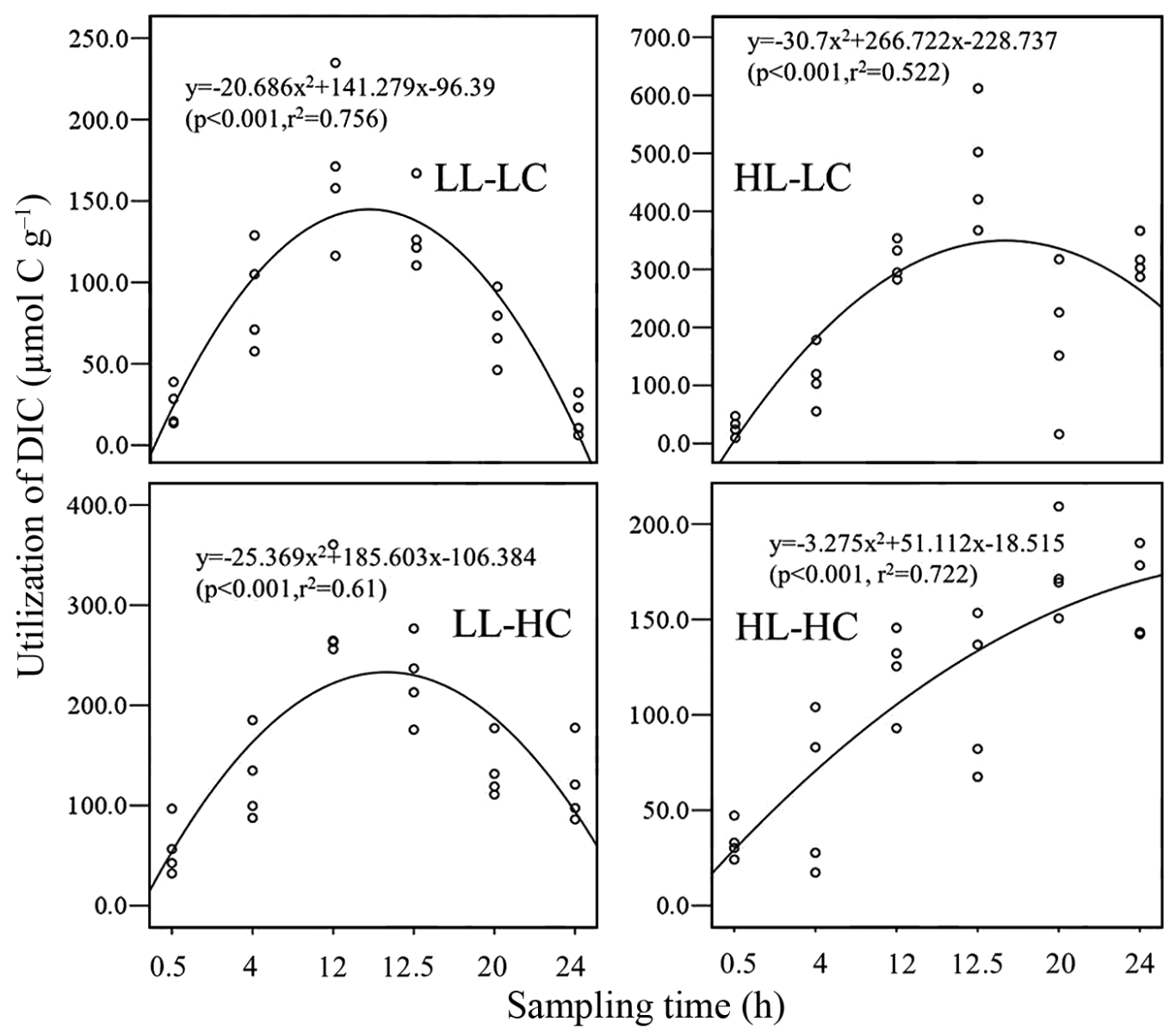

Fig. 2. Variations in the utilization of dissolved inorganic carbon (DIC; $\mu \mathrm{mol} \mathrm{C} \mathrm{g}^{-1}$ ) by thalli of Chara vulgaris with sampling time in 4 different treatments: LL-LC, LL-HC, HL-LC and HL-HC. Treatments are defined in Fig. 1 
Table 2. Coefficient and significance of Pearson's correlation between utilization of DIC ( $\mu \mathrm{mol} \mathrm{C} \mathrm{g}^{-1}$ ) and DIC concentra-

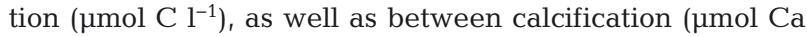
$\mathrm{g}^{-1}$ ) and DIC concentration in solution under 4 different treatment conditions. ${ }^{*} \mathrm{p}<0.05\left(2\right.$-tailed) ${ }_{i}{ }^{* *} \mathrm{p}<0.01$

\begin{tabular}{|lllll|}
\hline & LL-LC & LL-HC & HL-LC & HL-HC \\
\hline Utilization of DIC & $-0.498^{*}$ & $-0.536^{* *}$ & $-0.780^{* *}$ & $-0.427^{*}$ \\
Calcification & $-0.642^{*}$ & $-0.738^{* *}$ & -0.339 & -0.320 \\
\hline
\end{tabular}

\section{DISCUSSION}

\section{Daily rhythm of the calcification rate}

To date, no experiment under constant light intensity has addressed the daily rhythm of calcification of Chara thalli. Although many studies have been performed on coral calcification, revealing non-constant daily patterns of calcification rate, the results exhibited many specific-species differences (e.g. Moya et al. 2006, Al-Horani et al. 2007). Here, we found that under the constant light intensities of 90 and $150 \mu \mathrm{mol}$ photons $\mathrm{m}^{-2} \mathrm{~s}^{-1}$, the calcification rate of Chara thalli showed a continuous decrease during a $24 \mathrm{~h}$ period (light:dark, 12:12 h) at both DIC levels tested (Fig. 3). According to McConnaughey (1998), the calcification rate of Chara thalli is mainly affected by light intensity and $\mathrm{Ca}^{2+}$ and DIC concentrations in the solution. In the present study, to avoid the effect of $\mathrm{Ca}^{2+}$ and $\mathrm{Mg}^{2+}$ contents on calcification, $\mathrm{Ca}^{2+}$ content in the solution was above $60 \mathrm{mg} \mathrm{l}^{-1}$, while $\mathrm{Mg}^{2+}$ was below $30 \mathrm{mg}$ $\mathrm{l}^{-1}$ during the experiment (McConnaughey 1998, Kufel \& Kufel 2002, Gomes \& Asaeda 2010, Asaeda et al. 2014), and the light intensity did not change during the light period. Therefore, the effects of light intensity and $\mathrm{Ca}^{2+}$ and $\mathrm{Mg}^{2+}$ contents in the solution on photosynthesis and calcification were negligible. Thus, the observed decrease in calcifi-

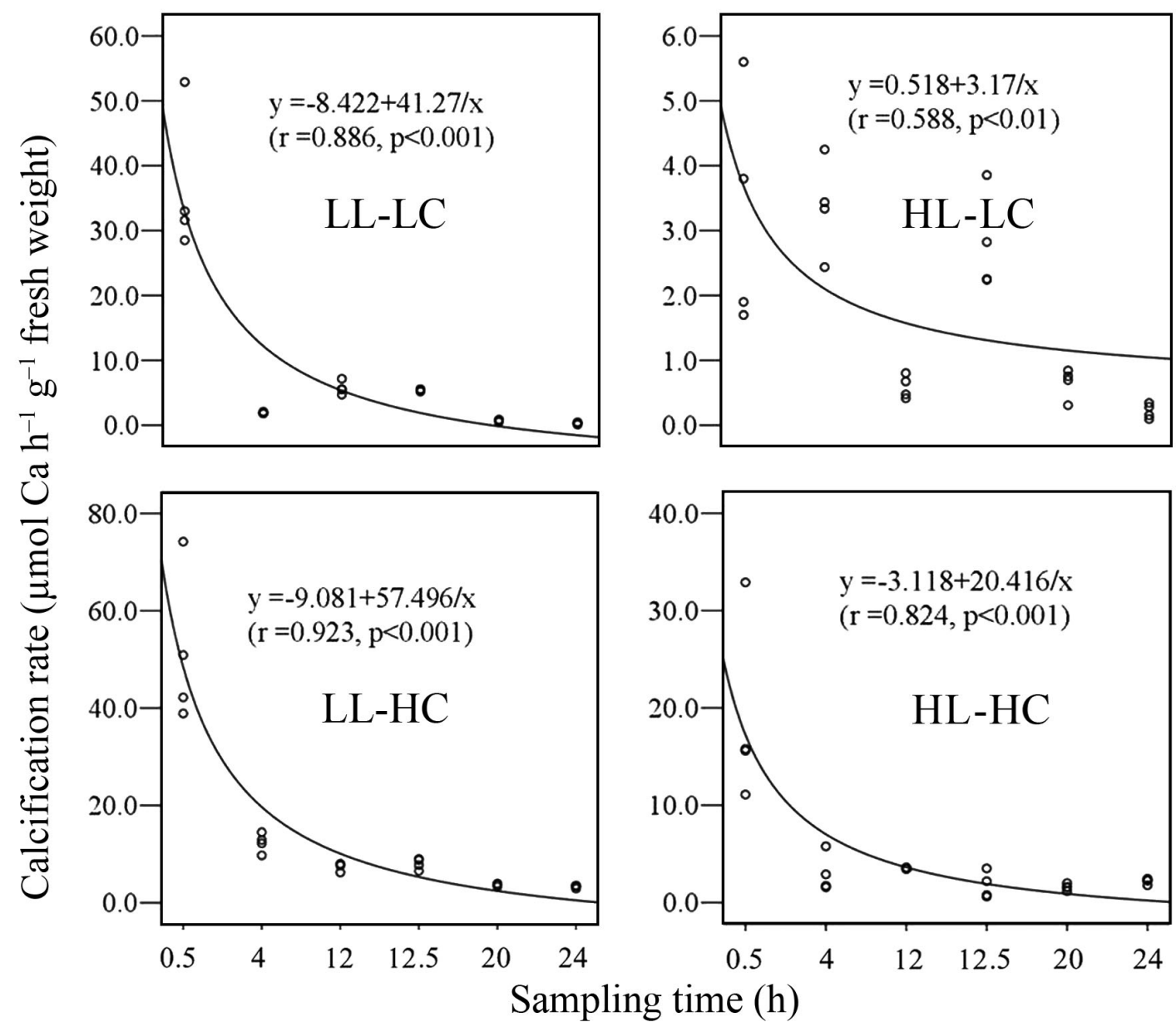

Fig. 3. Variations in calcification rate $\left(\mathrm{Ca}^{2+}{ }_{\text {uptakei }} \mu \mathrm{mol} \mathrm{Ca} \mathrm{h}^{-1} \mathrm{~g}^{-1}\right)$ by thalli of Chara vulgaris with time in 4 different treatments: LL-LC, LL-HC, HL-LC and HL-HC. Treatments are defined in Fig. 1 


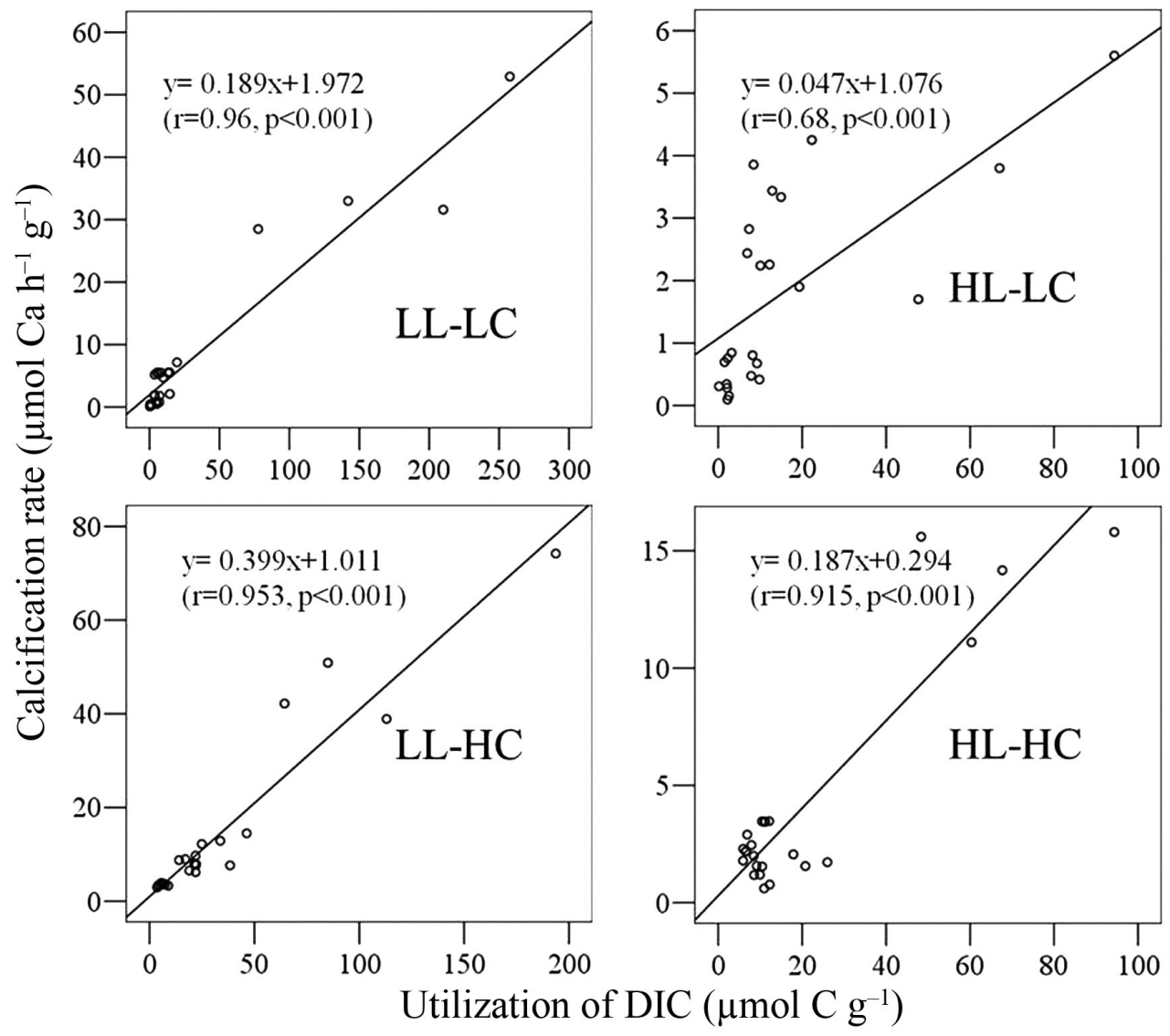

Fig. 4. Correlations between calcification rate $\left(\mathrm{Ca}^{2+}{ }_{\text {uptake}}\right)$ and the utilization rate of dissolved inorganic carbon (DIC $\mathrm{Cptake}$ $\mu \mathrm{mol} \mathrm{C} \mathrm{h} \mathrm{h}^{-1}$ ) for thalli of Chara vulgaris in 4 different treatments: LL-LC, LL-HC, HL-LC and HL-HC. Treatments are defined in Fig. 1

cation rate should be ascribed to a restriction in DIC concentration. This is further supported by a significant negative Pearson's correlation between calcification and DIC concentration under LL conditions and the much lower calcification rate found in the HL-LC treatment (Fig. 3). Our finding that external DIC concentration significantly affects the calcification rate of Chara thalli differs from the findings of previous studies that reported endogenous (plant body) inorganic carbon being used in the calcification of Chara (McConnaughey 1991). In addition, many studies of coral have shown that calcification is independent of exogenous DIC concentration (e.g. Furla et al. 2000). However, this independence of calcification on DIC content in the solution can be explained by the presence of sufficient inorganic carbon within the plants. In this study, endogenous inorganic carbon was exhausted during pre-treatment. Thus, external $\mathrm{HCO}_{3}{ }^{-}$showed a significant effect on the calcification rate of the plants.

\section{Dark calcification}

According to the trans-calcification models proposed by McConnaughey \& Whelan (1997), Chara calcification does not require light. However, to date no experimental study has provided direct data on dark calcification of Chara. In the dark, plant photosynthesis ceases completely and $\mathrm{CO}_{2}$ is produced by respiration; therefore, DIC uptake of the plants (calculated as the difference of DIC content in the solution with plants and the means of DIC content in 2 flasks without plants in the present study) from photosynthesis during the dark period would decrease resulting in reduced utilization of DIC. In other words, the increased utilization of DIC in the dark must result from calcification, as observed in HL-HC (Fig. 2). In our study, the calculation of the utilization of DIC did not take $\mathrm{CO}_{2}$ produced by dark respiration into consideration. Therefore, the utilization rate of DIC by calcification in darkness was underestimated. 

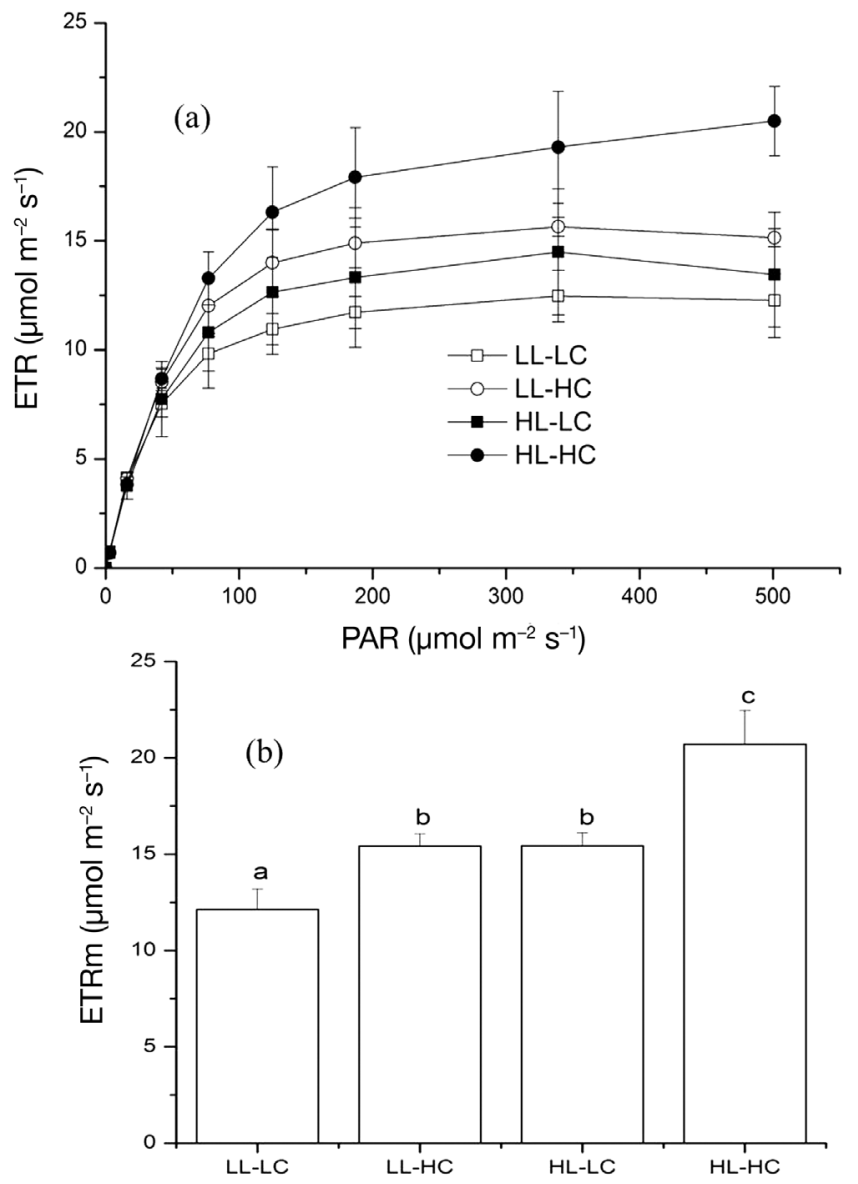

Fig. 5. (a) Electron transport rate (ETR) curves at 2 light levels (LL and HL) and 2 dissolved inorganic carbon (DIC) levels (LC and HC), and (b) maximum relative electron transport rate (rETRm) for these treatments for Chara vulgaris. Data are mean $\pm \mathrm{SD}(\mathrm{n}=4)$. Treatments are defined in Fig. 1

Although light is generally not considered to be necessary for calcification, higher calcification rates have been found in the light than in the dark for calcareous plants. This phenomenon is termed light-enhanced calcification and has already been described in some taxonomic groups, including scleractinian corals (e.g. Furla et al. 2000, Al-Horani et al. 2003, 2007), coccolithophorids (e.g. Nimer \& Merrett 1992, 1993), and Chara spp. (McConnaughey \& Falk 1991, Wang 2008). However, in our study, the calcification rate of Chara thalli under LL was higher than that under HL (Fig. 3). Light-enhanced calcification occurs through enhanced $\mathrm{O}_{2}$ production (Rinkevich \& Loya 1984) or pH change (Moya et al. 2006). For Chara plants, calcification accompanies the photosynthetic utilization of $\mathrm{HCO}_{3}^{-}$; therefore, calcification competes with photosynthesis for available DIC. The possible explanation for our finding that the calcification rate is
Table 3. F-values and significance of 2-way ANOVA of the effects of dissolved inorganic carbon (DIC) and light level on maximum relative electron transport rate (rETRm), photosynthetic rate in light-limited regions $(\alpha)$ and minimum saturating irradiance (Ek) of rapid light curves for Chara vulgaris thalli. ${ }^{* * *} \mathrm{p}<0.001,{ }^{* *} \mathrm{p}<0.01,{ }^{*} \mathrm{p}<0.5, \mathrm{~ns}: \mathrm{p}>0.5$

\begin{tabular}{|lcrr|}
\hline Parameter & DIC (D) & Light (L) & D $\times \mathrm{L}$ \\
\hline rETRm & $39.330^{* * *}$ & $23.766^{* * *}$ & $28.111^{* * *}$ \\
$\alpha$ & $0.765 \mathrm{~ns}$ & $2.266 \mathrm{~ns}$ & $0.676 \mathrm{~ns}$ \\
Ek & $8.849^{* *}$ & $14.473^{* * *}$ & $3.439 \mathrm{~ns}$ \\
\hline
\end{tabular}

lower under HL might be that, under LC, calcification is limited by the competitive capability of photosynthesis for DIC. This could also explain the higher calcification rate found in HL-HC than in HL-LC.

\section{Dependence of calcification on the utilization of DIC}

Here, we identified a linear correlation between calcification rate and the utilization rate of DIC (Fig. 3). Although a similar result has been reported in a coccolithophorid, the level of interaction between photosynthesis and calcification was taxondependent (Nimer \& Merrett 1992). We reported that a high competition for DIC between photosynthesis and calcification exists in Chara thalli (Wang et al. 2013), whereas no such competition was found in Stylophora pistillata microcolonies (McConnaughey \& Falk 1991, Furla et al. 2000). In the present study, the utilization of DIC resulted from photosynthesis and calcification of plants. We speculate that the high dependence of calcification on the utilization of DIC in Chara thalli was primarily related to the ratio of calcification to photosynthesis (C:P). A consequence of this is that any increase or decrease in the $\mathrm{C}: \mathrm{P}$ ratio by $\mathrm{HCO}_{3}{ }^{-}$addition causes a corresponding change in the calcification to DIC utilization ratio (Wang et al. 2013). According to our results, high light intensity and increased $\mathrm{HCO}_{3}{ }^{-}$likely affect the ratio of calcification to the utilization of DIC by affecting the C:P ratio.

Owing to the sound understanding of the relationships between fluorescence parameters and photosynthetic electron transport in vivo (Maxwell \& Johnson 2000, Baker 2008), RLCs of chlorophyll fluorescence can provide direct evidence about the effects of light level and additional $\mathrm{HCO}_{3}{ }^{-}$on photosynthesis in Chara thalli. In the present study, both light increase and addition of $\mathrm{HCO}_{3}{ }^{-}$significantly increased 
the ETRm and Ek of RLCs (Fig. 5), indicating that light and external DIC increased the photosynthetic rate and adaptive capacity of the plant to a high light level, which has been reported for some seagrasses (Björk et al. 1997, Schwarz et al. 2000). Our finding of a significant positive interaction on ETRm between light and $\mathrm{HCO}_{3}{ }^{-}$levels indicated that the photosynthetic performance of Chara thalli was the highest under both HL and HC.

Calcification in Chara thalli does not require light (McConnaughey \& Whelan 1997). Therefore, light increased the utilization of DIC by photosynthesis, resulting in decreased DIC utilization by calcification. Thus, the ratio of calcification to the utilization of DIC decreased at HL relative to LL (Fig. 4, Table 1). With $\mathrm{HCO}_{3}{ }^{-}$addition, both photosynthesis (Fig. 5) and calcification rate increased and resulted in increased utilization of DIC (Fig. 4). However, extant carbon added as $\mathrm{HCO}_{3}{ }^{-}$was preferentially incorporated into calcite (Sikes et al. 1980). This suggested a higher C:P ratio, and correspondingly, a higher ratio of calcification to the utilization of DIC for LL-HC and HL-HC treatments (Fig. 4). Results from $\mathrm{pH}$-drift experiments revealed that higher $\mathrm{HCO}_{3}{ }^{-}$-alkalinity suggested a stronger buffer capability (Kahara \& Vermaat 2003). Our finding that there is a significant decrease in the $\mathrm{pH}$ of the solution in response to additional $\mathrm{HCO}_{3}{ }^{-}$is in line with the findings of the $\mathrm{pH}$-drift experiments. This is also supported by the finding that external $\mathrm{HCO}_{3}{ }^{-}$inhibited the increase in solution $\mathrm{pH}$ by increasing calcification of calcareous plants, as reported by Wang et al. (2013).

\section{CONCLUSION}

Here, we showed that when endogenous inorganic carbon is exhausted, addition of $\mathrm{HCO}_{3}{ }^{-}$significantly promoted the calcification rate of Chara thalli. Calcification of $C$. vulgaris was primary restrained by $\mathrm{HCO}_{3}{ }^{-}$alkalinity in an open $24 \mathrm{~h}$ experiment. Furthermore, calcification of Chara thalli was dependent on the utilization of DIC; we propose that this dependence is determined by the ratio of calcification to photosynthesis affected by light level and DIC level. Therefore, calcification or $\mathrm{CaCO}_{3}$ encrustations of Chara might be a useful indication of water chemistry in the field.

Acknowledgements. We appreciate 3 anonymous reviewers for their useful suggestions about our manuscript. This research was supported by the National Natural Science Foundation of China (31670367, 41501297 and 31000161).

\section{LITERATURE CITED}

Al-Horani F, Al-Moghrabi S, de Beer D (2003) The mechanism of calcification and its relation to photosynthesis and respiration in the scleractinian coral Galaxea fascicularis. Mar Biol 142:419-426

Al-Horani F, Tambutté E, Allemand D (2007) Dark calcification and the daily rhythm of calcification in the scleractinian coral, Galaxea fascicularis. Coral Reefs 26: 531-538

Anadón P, Utrilla R, Vázquez A (2002) Mineralogy and SrMg geochemistry of charophyte carbonates: a new tool for paleolimnological research. Earth Planet Sci Lett 197: 205-214

Apolinarska K, Pelechaty M, Pukacz A (2011) $\mathrm{CaCO}_{3}$ sedimentation by modern charophytes (Characeae): Can calcified remains and carbonate $\delta^{13} \mathrm{C}$ and $\delta^{18} \mathrm{O}$ record the ecological state of lakes? - a review. Stud Limnol Telmatol 5:55-66

Asaeda T, Senavirathna MDHJ, Rashid MH (2014) Effect of calcium and magnesium on the growth and calcite encrustation of Chara fibrosa. Aquat Bot 113:100-106

Baker NR (2008) Chlorophyll fluorescence: a probe of photosynthesis in vivo. Annu Rev Plant Biol 59:89-113

Beer S, Axelsson L (2004) Limitations in the use of PAM fluorometry for measuring photosynthetic rates of macroalgae at high irradiances. Eur J Phycol 39:1-7

Björk M, Weil A, Semesi S, Beer S (1997) Photosynthetic utilisation of inorganic carbon by seagrasses from Zanzibar, East Africa. Mar Biol 129:363-366

B Blindow I (1992) Long- and short-term dynamics of submerged macrophytes in two shallow eutrophic lakes. Freshw Biol 28:15-27

* Durako MJ, Kunzelman JI (2002) Photosynthetic characteristics of Thalassia testudinum measured in situ by pulseamplitude modulated (PAM) fluorometry: methodological and scale-based considerations. Aquat Bot 73:173-185

F Feng F, Fang T, Liu JT (2006) Vertical distribution of species of nitrogen and phosphorus in the sediments of Lake Donghu. Environ Sci 27:1078-1082 (in Chinese with English Abstract)

F Furla P, Galgani I, Durand I, Allemand D (2000) Sources and mechanisms of inorganic carbon transport for coral calcification and photosynthesis. J Exp Biol 203:3445-3457

*Gomes PIA, Asaeda T (2010) Impact of calcium and magnesium on growth and morphological acclimations of Nitella: implications for calcification and nutrient dynamics. Chem Ecol 26:479-491

Hutchinson GE (1975) A treatise on limnology. 3. Limnological botany. John Wiley \& Sons, New York, NY

Kahara SN, Vermaat JE (2003) The effect of alkalinity on photosynthesis-light curves and inorganic carbon extraction capacity of freshwater macrophytes. Aquat Bot 75: 217-227

*KKawahata C, Yamamuro M, Shiraiwa Y (2013) Changes in alkaline band formation and calcification of corticated charophyte Chara globularis. SpringerPlus 2:85-90

Kufel L, Kufel I (2002) Chara beds acting as nutrient sinks in shallow lakes - a review. Aquat Bot 72:249-260

*Kufel L, Strzałek M (2016) Site- and species-specific contribution of charophytes to calcium and phosphorus cycling in lakes. Hydrobiologia 767:185-195

K Kufel L, Biardzka E, Strzałek M (2013) Calcium carbonate incrustation and phosphorus fractions in five charophyte species. Aquat Bot 109:54-57 
Maxwell K, Johnson GN (2000) Chlorophyll fluorescencea practical guide. J Exp Bot 51:659-668

McConnaughey T (1991) Calcification in Chara corallina: $\mathrm{CO}_{2}$ hydroxylation generates protons for bicarbonate assimilation. Limnol Oceanogr 36:619-628

McConnaughey T (1998) Acid secretion, calcification, and photosynthetic carbon concentrating mechanisms. Can J Bot 76:1119-1126

McConnaughey TA, Falk RH (1991) Calcium-proton exchange during algal calcification. Biol Bull (Woods Hole) 180:185-195

McConnaughey T, Whelan J (1997) Calcification generates protons for nutrient and bicarbonate uptake. Earth Sci Rev 42:95-117

Moya A, Tambutté S, Tambutté E, Zoccola D, Caminiti N, Allemand D (2006) Study of calcification during a daily cycle of the coral Stylophora pistillata: implications for light-enhanced calcification. J Exp Biol 209:3413-3419

Nimer N, Merrett M (1992) Calcification and utilization of inorganic carbon by the coccolithophorid Emiliania huxleyi Lohmann. New Phytol 121:173-177

Nimer N, Merrett M (1993) Calcification rate in Emiliania huxleyi Lohmann in response to light, nitrate and availability of inorganic carbon. New Phytol 123:673-677

Pelechaty M, Pukacz A, Apolinarska K, Pelechata A, Siepak M (2013) The significance of Chara vegetation in the precipitation of lacustrine calcium carbonate. Sedimentology 60:1017-1035

Platt T, Gallegos C, Harrison WG (1980) Photoinhibition of photosynthesis in natural assemblages of marine phytoplankton. J Mar Res 38:687-701

Ralph PJ, Gademann R (2005) Rapid light curves: a powerful tool to assess photosynthetic activity. Aquat Bot 82:222-237

Ray S, Klenell M, Choo KS, Pedersén M, Snoeijs P (2003) Carbon acquisition mechanisms in Chara tomentosa. Aquat Bot 76:141-154

Rinkevich B, Loya Y (1984) Does light enhance calcification

Editorial responsibility: Brant Touchette,

Elon, North Carolina, USA in hermatypic corals? Mar Biol 80:1-6

* Schwarz AM, Björk M, Buluda T, Mtolera M, Beer S (2000) Photosynthetic utilisation of carbon and light by two tropical seagrass species as measured in situ. Mar Biol 137:755-761

Sikes CS, Roer RD, Wilbur KM (1980) Photosynthesis and coccolith formation: inorganic carbon sources and net inorganic reaction of deposition. Limnol Oceanogr 25: $248-261$

Siong K, Asaeda T (2006) Does calcite encrustation in Chara provide a phosphorus nutrient sink? J Environ Qual 35: 490-494

* Siong K, Asaeda T (2009a) Effect of magnesium on charophytes calcification: implications for phosphorus speciation stored in biomass and sediment in Myall Lake (Australia). Hydrobiologia 632:247-259

* Siong K, Asaeda T (2009b) Calcite encrustation in macroalgae Chara and its implication to the formation of carbonate-bound cadmium. J Hazard Mater 167:1237-1241

Urbaniak J (2010) Estimation of carbonate and element content in charophytes - methods of determination. Pol J Environ Stud 19:413-417

Wang HY (2008) The eco-physiological responses to environmental factors of charophyte plants in shallow lake of the middle reach of the Yangtze River. PhD dissertation, Wuhan University

*Wang HY, Yu D, Xiao KY (2008) The interactive effects of irradiance and photoperiod on Chara vulgaris L.: concerted responses in morphology, physiology, and reproduction. Hydrobiologia 610:33-41

Wang HY, Ni LY, Xie P (2013) The mitigating effect of calcification-dependent of utilization of inorganic carbon of Chara vulgaris Linn on $\mathrm{NH}_{4}-\mathrm{N}$ toxicity. Chemosphere 93: 373-379

Wood RD, Imahori K (1965) Monograph of the Characeae, Vol 1. In: Wood RD, Imahori K (eds) A revision of the Characeae. Cramer, Weinheim, p 1-20

Submitted: January 2, 2017; Accepted: August 11, 2017 Proofs received from author(s): October 11, 2017 